\title{
Liver transplantation for homozygous familial hypercholesterolaemia
}

\author{
S P Revell, G Noble-Jamieson, P Johnston, A Rasmussen, N Jamieson, N D Barnes
}

\begin{abstract}
Homozygous familial hypercholesterolaemia is a rare inherited condition with an incidence of approximately one in a million. It is associated with severe premature atherosclerosis and early death from cardiovascular complications. The results of liver transplantation reported to date have suggested only partially effective reduction of the hypercholesterolaemia.

Three boys with familial hypercholesterolaemia, aged 10.0 to 15.1 years, received liver grafts at Addenbrooke's Hospital. Their untreated fasting lipid concentrations were grossly raised. All three had angiographic evidence of coronary atheroma and two had exertional angina. One child had such severe atheroma that coronary artery bypass surgery was considered necessary before liver transplantation. All three had straightforward operative and postoperative courses and their lipid concentrations returned rapidly to normal. One boy developed chronic rejection requiring retransplantation. Currently all three boys are well, on normal diets, and with normal liver function.

It is concluded that (1) liver transplantation offers highly effective treatment for this lethal condition, (2) timing the operation is difficult but it should be undertaken before coronary artery disease has progressed too far (when combined liver and heart transplantation may be the only possibility), and (3) in well grown children with no previous abdominal surgery the immediate risks of liver transplantation are low but chronic rejection remains a danger.

(Arch Dis Child 1995; 73: 456-458)
\end{abstract}

Keywords: liver transplantation, familial hypercholesterolaemia.

Addenbrookes NHS Trust, Cambridge, Department of Paediatrics A P Revell G Noble-Jamieson N D Barnes

Department of Surgery

P Johnston

A Rasmussen

N Jamieson

Correspondence to: Dr G Noble-Jamieson, Paediatric Department, Addenbrookes NHS Trust, Hills Road, Cambridge CB2 2QQ

Accepted 12 July 1995 lar problems. No safe, effective medical treatment is currently available. ${ }^{1}$ Liver transplantation has the potential to correct the metabolic abnormality but the results reported to date have been equivocal with only partial correction of the lipid abnormality. ${ }^{2}$

We describe three children in whom liver transplantation fully corrected the lipid abnormality.

\section{Case reports}

PATIENT 1

This English boy developed xanthomata at 11 months of age and was found to have the typical lipid profile of homozygous familial hypercholesterolaemia. Initially he was treated with a low fat diet only but from the age of 9 years cholestyramine and nicotinic acid were added. Coronary angiography was normal at that time but when repeated four years later showed a $30 \%$ stenosis of the proximal left descending coronary artery. He remained asymptomatic and no ischaemic changes were seen on an electrocardiogram (ECG). His treatment was intensified and for two years he had weekly plasma exchanges. Although this produced a satisfactory fall in lipid concentrations he found the treatment extremely burdensome and it was complicated by multiple central line infections. $\mathrm{He}$ was therefore referred for consideration of liver transplantation.

He received a whole liver graft in October 1990 and had an uncomplicated perioperative course. The donor was cytomegalovirus positive and the patient developed cytomegalovirus hepatitis which resolved fully after a course of ganciclovir. His lipid profile and liver function returned to normal two weeks after transplantation (table and figure). He was well and had a normal lipid profile and normal liver function 3.8 years after the operation.

\section{PATIENT 2}

This Asian son of a first cousin marriage developed xanthomata at the age of 6 years and was found to have familial hypercholesterolaemia. In spite of treatment with a low fat diet, cholestyramine and simvastatin, his cholesterol remained greatly raised. Coronary angiography at the age of 9 showed atheromatous changes of the left coronary artery and the descending aorta and also a $50-70 \%$ stenosis of the inferior mesenteric artery. There was a chronic dissection of the aorta below the renal arteries which was presumed to have occurred as a complication of angiography. He was referred for transplantation.

He received a whole liver graft in April 1992 and made a rapid recovery. He was hypertensive postoperatively and required treatment with nifedipine and atenolol. His lipid concen- 
Serum lipid concentrations ${ }^{\star}$ at diagnosis, assessment, and after liver transplantation (all values are mmoll)

\begin{tabular}{|c|c|c|c|c|c|c|}
\hline & \multicolumn{2}{|c|}{ Before transplant } & \multicolumn{4}{|c|}{ After transplant } \\
\hline & Diagnosis & Assessment & 1 Week & 2 Weeks & 1 Month & 6 Months \\
\hline \multicolumn{7}{|l|}{ Patient 1} \\
\hline $\begin{array}{l}\text { Total cholesterol } \\
\text { Triglyceride } \\
\text { HDL cholesterol } \\
\text { LDL cholesterol }\end{array}$ & $18 \cdot 0$ & $\begin{array}{r}20 \cdot 8 \\
1 \cdot 8 \\
0 \cdot 8 \\
19 \cdot 2\end{array}$ & $\begin{array}{r}10 \cdot 2 \\
4 \cdot 6\end{array}$ & $\begin{array}{l}5 \cdot 8 \\
3 \cdot 5 \\
0 \cdot 5 \\
3 \cdot 7\end{array}$ & $\begin{array}{l}6 \cdot 0 \\
3 \cdot 2 \\
0 \cdot 6 \\
3 \cdot 9\end{array}$ & $\begin{array}{l}5 \cdot 6 \\
1.5 \\
1.0 \\
3.9\end{array}$ \\
\hline \multicolumn{7}{|l|}{ Patient 2} \\
\hline $\begin{array}{l}\text { Total cholesterol } \\
\text { Triglyceride } \\
\text { HDL cholesterol } \\
\text { LDL cholesterol }\end{array}$ & $20 \cdot 0$ & $\begin{array}{r}25 \cdot 6 \\
2 \cdot 0 \\
0 \cdot 5 \\
24 \cdot 2\end{array}$ & $\begin{array}{r}13 \cdot 9 \\
0.5 \\
0.5 \\
13 \cdot 2\end{array}$ & $4 \cdot 8$ & $\begin{array}{l}5 \cdot 2 \\
2 \cdot 1 \\
1 \cdot 0 \\
3 \cdot 3\end{array}$ & $\begin{array}{l}5 \cdot 6 \\
0 \cdot 8 \\
1 \cdot 7 \\
3 \cdot 5\end{array}$ \\
\hline \multicolumn{7}{|l|}{ Patient 3} \\
\hline $\begin{array}{l}\text { Total cholesterol } \\
\text { Triglyceride } \\
\text { HDL cholesterol }\end{array}$ & NA & $\begin{array}{r}23.9 \\
0.8 \\
0.7\end{array}$ & $\begin{array}{l}6 \cdot 9 \\
2 \cdot 2 \\
0 \cdot 6\end{array}$ & $\begin{array}{l}5 \cdot 0 \\
2 \cdot 2 \\
0 \cdot 9\end{array}$ & $\begin{array}{l}6 \cdot 7 \\
1.4 \\
1.8\end{array}$ & $\begin{array}{l}5 \cdot 7 \\
2 \cdot 0 \\
1 \cdot 3\end{array}$ \\
\hline LDL cholesterol & & $22 \cdot 9$ & $5 \cdot 3$ & $3 \cdot 1$ & $4 \cdot 3$ & 3.5 \\
\hline
\end{tabular}

*Normal ranges - total cholesterol $(\mathrm{mmol} / \mathrm{l})$ : desirable $<5 \cdot 2$, abnormal $>7 \cdot 8$; triglyceride $(\mathrm{mmol} / \mathrm{l})$ : desirable $<2 \cdot 0$, abnormal $>4 \cdot 0 ; H D L$ cholesterol $(\mathrm{mmol} / \mathrm{l})$ : desirable $>1 \cdot 0$, abnormal $<0 \cdot 9 ; L D L$ cholesterol $(\mathrm{mmol} / 1)$ : desirable $<4 \cdot 0$, abnormal $>5 \cdot 5$.

trations and his graft function were normal by the second postoperative week. He was discharged only three weeks postoperatively. $\mathrm{He}$ had little family support and on treatment with cyclosporin he had developed hypertrichosis and for this reason he probably did not take his immunosuppressive drugs consistently. Ten months later he became jaundiced and a liver biopsy specimen showed the changes of advanced chronic rejection. His condition deteriorated rapidly and he was retransplanted with a reduced liver graft as an emergency as he was suffering from deep jaundice, coagulopathy, encephalopathy, and intrahepatic sepsis. Postoperatively he had an episode of septicaemia but recovered and was discharged well with normal graft function after only four weeks. He was extremely well one year after his second transplant and with close supervision has taken his immunosuppressive drugs reliably.

\section{PATIENT 3}

This Greek boy developed extensive xanthomata from the age of 3 years and familial hypercholesterolaemia was diagnosed. $\mathrm{He}$ was treated with a low fat diet and cholestyramine but this had little effect on his cholesterol concentrations. From 11 years of age he developed exertional angina and was referred to the Brompton Hospital in London. An exercise stressed ECG showed severe ischaemic changes and coronary angiography demonstrated

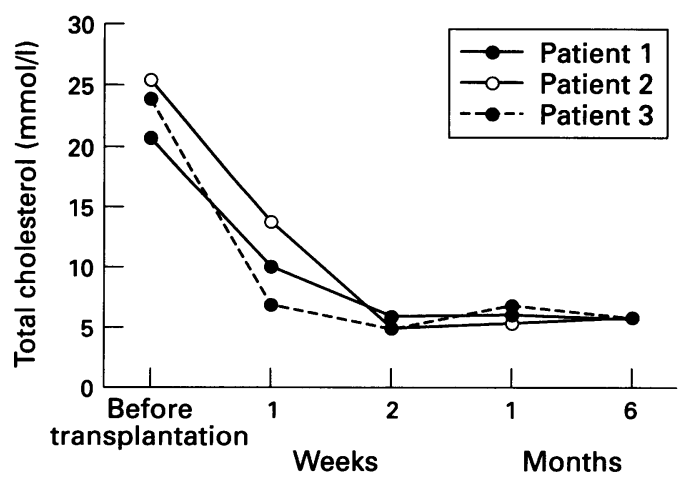

Total cholesterol before and after liver transplantation. stenosis of all three coronary arteries and the supravalvar aorta. $\mathrm{He}$ was referred to Cambridge for consideration of combined heart and liver transplantation. On cardiological review it was felt that because of his good left ventricular function bypass surgery would be appropriate. He had successful quadruple coronary artery bypass surgery and patch aortoplasty at Papworth Hospital. Two months later in November 1991 he received a liver graft without any anaesthetic or surgical problems. Apart from transient hypertension he had no postoperative problems and was discharged three weeks later with normal graft function and normal blood lipid concentrations.

All these three children remain well with normal graft function from 12 to 45 months (mean 30 months) after liver transplantation. Their blood lipid concentrations remained normal without the need for any additional dietary modifications or lipid lowering drugs. In all children skin xanthomata disappeared within one year and in the child who had coronary artery bypass surgery reversal of atheromatous lesions was also demonstrated angiographically.

In summary, before transplantation these three children had grossly raised total serum cholesterol values, up to five times greater than the upper limit of the normal range, with low density lipoprotein (LDL) fractions similarly raised and high density lipoprotein (HDL) fractions low. Transplantation promptly returned the serum lipid values to normal, with the lowering of both total and LDL cholesterol and raising of HDL cholesterol (table and figure).

\section{Discussion}

Family hypercholesterolaemia is caused by a mutant gene on chromosome 19 coding for the structure of the LDL receptor. ${ }^{3}$ This gene is found in approximately one in 500 of the population. A number of mutant alleles have been identified, the commonest resulting in absence of the LDL receptors, while others result in reduced numbers or abnormal function of receptors. Heterozygotes have total serum cholesterol concentrations approximately double the normal range $(7-3 \mathrm{mmol} / \mathrm{l})$. In the homozygous state, which occurs in only one in a million of the population, the cholesterol concentrations are much higher, ranging from approximately 18 to $26 \mathrm{mmol} / \mathrm{l}$.

In the normal individuals, raised concentrations of LDL in the circulation induce the formation of increased numbers of $\mathrm{LDL}$ receptors on cell surfaces. The majority of these receptors $(50-75 \%)$ are located in the liver. ${ }^{4}$ Heterozygotes have only half the normal number of LDL receptors, and develop slowly progressive atherosclerosis, which usually becomes symptomatic in the fourth or fifth decade of life. In homozygotes, atheroma progress much more rapidly, with symptoms of angina or even death occurring from coronary artery occlusions within the first two decades of life. The manifestations may include corneal 
arcus and the formation of tuberous xanthoma over tendons and pressure areas.

Treatment options for familial hypercholesterolaemia include diet, drugs, plasmapheresis, bypass surgery, and liver transplantation. ${ }^{5}$ Since the gene has been localised, gene therapy may become the treatment of choice for the future. The first patient who has received successful ex vivo gene therapy has recently been reported. 6

Diet is of most benefit to patients with mildly raised serum lipids and has only a supporting role in the treatment of familial hypercholesterolaemia. Drugs used in the treatment of hypercholesterolaemia are of two main types: bile acid sequestrants and LDL receptor modifying agents. Bile acid sequestrants lower serum cholesterol by up to $20 \%$ and therefore are used as an adjunctive treatment in familial hypercholesterolaemia. They are also unpalatable, cause steatorrhoea, and prevent absorption of various nutrients, particularly the fat soluble vitamins. LDL receptor modifying agents are ineffective in this condition because the receptors are absent in homozygous familial hypercholesterolaemia.

Plasmapheresis removes cholesterol from the circulation and can lower the concentrations to two thirds of their pretreatment values. ${ }^{7}$ This remains a useful therapeutic option over the short term, chiefly to delay the development of atheroma before more definitive treatment. The effect of plasmapheresis is short lived, and requires twice weekly repetition to maintain satisfactory values; and there is the additional problem of long term venous access.

Partial ileal bypass, with a view to limiting the enterohepatic circulation of bile acids, has been described. ${ }^{8}$ This treatment was reported to lower serum cholesterol by a quarter to a third and so only delays the inevitable progression of atherosclerosis. It also has adverse effects on growth and development.

Portocaval shunting, initially reported by Starzl et $a l,{ }^{9}$ reduces total and LDL cholesterol by approximately a third, through altering hepatic cholesterol and lipoprotein metabolism. This procedure requires major surgery and has inherent complications; in addition, it may complicate later transplantation. In view of the complications inherent in these forms of surgery for familial hypercholesterolaemia, these procedures have been largely abandoned.

Liver transplantation is a therapeutic option for familial hypercholesterolaemia because the majority of LDL receptors are located in the liver and transplanted hepatocytes retain their original metabolic specificity. It was first described in a single patient in 1984, when a simultaneous heart transplant was performed. ${ }^{2}$ Since then three further patients have received combined liver and heart grafts. ${ }^{1011}$ The use of coronary revascularisation has also been described. ${ }^{12}$ Heart transplantation is associated with accelerated coronary vascular atheroma. ${ }^{13}$ In those patients who survived a reduction of cholesterol to near normal values (an $80 \%$ reduction of pretransplant values) was recorded, one patient requiring further lipid lowering medication. ${ }^{14}$ There is also a report of a 4 year old child who received isolated liver transplantation followed by a fall in cholesterol values to within the normal range. ${ }^{15}$ In all three of our patients, the total and LDL cholesterol concentrations fell rapidly to normal and stayed there.

In conclusion, liver transplantation offers a highly effective treatment for this lethal condition and seems likely to remain the treatment of choice until gene therapy becomes a viable alternative. The timing of the operation is difficult but it should be considered once there is angiographic evidence of atheromatous disease, even in the absence of exertional angina. In well grown children with no previous abdominal surgery, the immediate risks of liver transplantation are low but long term complications such as chronic rejection remain a danger. After successful transplantation there may be a remarkable regression of established atheromatous lesions.

1 Dunnigan MG. The problem with cholesterol. BMF 1993; 306: 1355-6.

2 Starzl TE, Bahnson HT, Hardesty RL, et al. Heart-liver transplantation in a patient with familial hypercholesterolemia. Lancet 1984; i: 1382-3.

3 Francke U, Brown MS, Goldstein JL. Assignment of the human gene for low density lipoprotein receptor to chromosome 19: synteny of a receptor, a ligand and a genetic disease. Proc Natl Acad Sci USA 1984; 81: 2826-30.

4 Brown MS, Goldstein JL. A receptor mediated pathway for cholesterol homeostasis. Science 1986; 232: 34-47.

5 Hoeg JM. Pharmacologic and surgical treatment of dyslipidaemic children and adolescents. Ann NY Acad Sci 1991; 623: 275-84

6 Grossman M, Raper SE, Kozarsky K, et al. Successful ex vivo gene therapy directed to liver in a patient with familial hypercholesterolaemia. Nature Genetics 1994; 6: 335-41.

7 Hoeg JM, Starzl TE, Brewer HB. Liver transplantation for treatment of cardiovascular disease: comparison with medication and plasma exchange in homozygous familial hypercholesterolaemia. Am f Cardiol 1987; 59: 705-7.

8 Buchwald $\mathrm{H}$. Lowering of cholesterol absorption and blood levels by ileal exclusion: experimental basis and preliminary clinical report. Circulation 1964; 29: 713-20.

9 Starzl TE, Putnam CW, Chase HP, Porter KA. Portacaval shunting in hyperlipoproteinaemia. Lancet 1973; ii: shunting

10 Shaw BW, Bahson HT, Hardesty RL, Griffith BP, Starzl TE. Combined transplantation of the heart and Starzl TE. Combined transplanta
liver. Ann Surg 1985; 202: 667-72.

11 Figuera D, Ardaiz J, Martin-Judez V, et al. Combined transplantation of heart and liver from two different donors in a patient with familial type IIa hypercholesterolaemia. f Heart Transplant 1986; 5: 327-9.

12 Brush JE, Leon MB, Starzyl TE, Gill C, Hoeg JM. Successful treatment of angina pectoris with liver transplantation and bilateral internal mammary bypass graft surgery in familial hypercholesterolaemia. Am Heart $\mathfrak{f}$ 1988; 116: 365-7.

13 Griepp RB, Stison EB, Bieber CP. Control of graft atherosclerosis in human heart transplant recipients. Surgery 1977; 81: 262-9.

14 East C, Grundy SM, Bilheimer DW. Normal cholesterol levels with lovastatin (mevinolin) therapy in a child with homozygous familial hypercholesterolaem

15 Sokal EM, Ulla L, Harvengt C, Otte JB. Liver transplantation for familial hypercholesterolaemia before the onset of cardiovascular complications. Transplantation 1993; 55: 432-3. 